\title{
Los argumentos de la critica regionalista al sistema caciquil en la opinión pública gaditana durante los años de la Restauración
}

\author{
JULIO PEREZ SERRANO
}

\section{UN ENFOQUE PARTICULAR DE LA CUESTION}

En los años que van de 1875 a 1923 se consolida en España el régimen político, social y económico que, haciendo referencia a su componente dinástico, conocemos con el nombre de Restauración. En estos años germinan, se desarrollan y llegan a entrar en conflicto dos tendencias que habrán de marcar de manera indeleble la historia de Andalucía en el primer tercio de nuestro siglo. De un lado, el caciquismo, con todo lo que podemos considerar asociado a él ${ }^{1}$. De otro, el naciente regionalismo, intimamente relacionado con el ideal regeneracionista ${ }^{2}$, todavía poco definido en lo político, pero fuertemente enraizado en la cultura y las tradiciones populares.

Aunque se trata de fenómenos constatables también en otras regiones españolas, en Andalucía ambas realidades manifiestan caracteres específicos $^{3}$. La primera, como piedra angular del sistema que garantiza el reparto de poder y el modelo de convivencia impuesto por los grandes propietarios tras el fracaso de la experiencia democrática iniciada en 1868. La segunda, como repuesta crítica al sistema, en pugna con republicanos, anarquistas, socialistas y católicos por alcanzar la hegemonía entre las fuerzas políticas de oposición al "turnismo".

(1) Es decir, el encasillado. y el ppucherazo como mecanismos esenciales de la vida política, el control oligárquico de las instituciones representativas, la impotencia de la oposición para ganarse el apoyo de las masas...

(2) Véase, por ejemplo, INFANTE, B.: La obra de Costa. Un breve estudio leído en el Ateneo de Sevilla en el V Aniversario de la muerte de Costa. Sevilla, 1916.

(3) Cfr. TUSELL, J.: EEl sistema caciquil andaluz comparado con el de otras regiones españolas (1903-1923). En: Actas del I Congreso de Historia de Andalucia. Andalucia contemporánea (siglos XXX y XX). II. Córdoba, 1979, pp. 551-560. 
Ni que decir tiene que la influencia del sistema caciquil en Andalucía fue muy grande en todos los órdenes ${ }^{4}$, determinando no sólo el funcionamiento viciado de los mecanismos electorales, sino también las relaciones de desigualdad entre las clases, el anquilosamiento de las estructuras económicas y, en buena medida, la propia manera de ser y de pensar de los andaluces.

El regionalismo, por su parte, se fue abriendo paso en el terreno político muy lentamente, debiendo superar los innumerables obstáculos que dificultaban la traducción de la larga experiencia colectiva de los andaluces como pueblo -plasmada, sin embargo, nítidamente en las costumbres y las tradiciones culturales- en un programa específico de reformas orientado a la acción. Inevitablemente el ataque del naciente andalucismo a las estructuras de poder existentes pronto lo llevará a denunciar el fenómeno que en gran medida había alimentado su desarrollo y que se presentaba a sus ojos como la principal lacra del sistema que los andalucistas pretendían regenerar ${ }^{5}$.

Conocemos bastante bien los principales ejes teóricos y políticos de la crítica andalucista al sistema político, social y económico de la Restauración, pues contamos con múltiples estudios que abordan total o parcialmente esta temática ${ }^{6}$. Sin embargo, en línea con el objetivo de edificar la historia desde abajo, debemos reconocer que no poseemos la misma certeza acerca de cuál fue el grado y el ritmo con que esta crítica penetró realmente en -o, mejor, sintonizó con- la opinión pública andaluza.

Sabemos que el andalucismo militante logró articular bien poco en Cádiz hasta el advenimiento de la II República, e incluso después; basta comparar su influencia con la de otras corrientes opositoras, por ejemplo, con el socialismo o el anarquismo. Pero, aunque en efecto la mayoría social se muestra indiferente ante el programa político del regionalismo andaluz, un análisis más detenido de las opiniones y críticas presentes en las publicaciones de la época, no las vinculadas al movimiento

(4) Cfr. IDEM: Oligarquia y caciquismo en Andalucia (1890-1923). Barcelona, 1976, pp. 499 ss.

(5) Tal es el espí itu de la llamada Constitución de Antequera, Vid. ACOSTA SANCHEZ, J.:La Constitución de Antequera. Estudio teórico-crítico. Democracia, federalismo y andalucismo en la España contemporánea. Sevilla, 198j. También, MILLAN CHIVITE, J. L.: -Sociedad e ideología en torno a la Constitución federal de los cantones andaluces. En: Actas del I Congreso sobre el Andalucismo Histórico. Sevilla, 1984, pp. 217-227.

(6) Los posicionamientos regionalistas que van apareciendo sucesivamente en la Constitución de Antequera de 1883, el Congreso Georgista de Ronda de 1913, el Primer Congreso Andaluz de 1918, la Asamblea de Córdoba de 1919, las obras de Blas Infante o las publicaciones de inspiración andalucista que proliferan en el primer tercio del XIX han sido ya objeto de un numeroso elenco de trabajos que sería muy prolijo detallar. 
andalucista ${ }^{7}$, sino las de mayor tirada, ideológicamente eclécticas e incluso afines a otras tendencias, revela que los argumentos de los andalucistas eran sin embargo compartidos por un elevado número de personas; número que crece a medida que se va haciendo patente la crisis del modelo político de la Restauración. Y ello en una ciudad que había vivido siempre de espaldas a su entorno regional y que, por ello, abrazó con poco entusiasmo y tardíamente el ideal andalucista ${ }^{8}$.

Pensamos que la estrategia de seguir la crítica al sistema caciquil a través de la prensa local no específicamente andalucista nos permitirá dimensionar qué respaldo potencial llegó a poseer el discurso andalucista en la opinión pública gaditana, con independencia de que, por otras razones, este respaldo no lograra traducirse, como de hecho no lo hizo, en desarrollo orgánico e influencia electoral.

\section{EL CACIQUISMO GADITANO: CONTROI POLITICO, REPRESION E INDIFERENCIA DE LAS AUTORIDADES ANTE LA CRISIS}

Quienes lo han estudiado con mayor detenimiento señalan que durante los años de la Restauración tomó cuerpo en Cádiz un sistema susceptible de ser definido como :caciquismo integral, en cuanto se enroscó en todos los entresijos de la sociedad gaditana". Será, como en otras zonas, la fecha de 1890 la que marcará, si no el inicio, sí el advenimiento de una nueva etapa donde el fenómeno caciquil adquiera los rasgos más característicos de su fisonomía ${ }^{10}$. Dos grandes familias, cuyos máximos exponentes fueron tres personajes, Cayetano del Toro y los hermanos Gómez de Aramburu, que controlaron los dos partidos del turno, monopolizaron el poder político en la ciudad durante el último cuarto del siglo XIX; control político y preeminencia social que habrían de verse continuados en el caso

(7) Entre tales revistas destacán las de la década de 1913-23: Andalucía, Bética, La'Exposición, Córdoba, Avante, El Regionalismo, El Justiciero, Andalucía Futura, Andalucía Federal, Nueva Andalucia, La Voż del Pueblo, El Guadalquivir, etc... Cf r. LACOMBA, J.A.: -Los orígenes del Andalucismo y el debate sobre el regionalismo en Andalucía. Revista de estudios regionales, 2 (1981), pp. 134 ss.

(8) Cfr. PEREZ SERRANO, J.: -Gaditanismo y andalucismo. Orígenes de la conciencia andaluza en el Cádiz de la Restauración borbónica. En: Andalucia ayer y boy. Actas del III Congreso sobre el Andalucismo Histórico. Sevilla, 1989, pp. 409-411.

(9) MILLAN CHIVITE, J. L.: •El Cádiz polémico de la Restauración.. En: MILLAN CHIVITE, J. L.: El Casino y la ciudad de Cádiz. Polútica, sociedad y cultura en el Cádiz del siglo XIX. Cádiz, 1986, p. 67.

(10) El caciquismo se vio favorecido por la ley electoral de 1890 , ya que ta aplicación del sufragio universal quedó en manos de un sector de la burguesía que integraba la élite política., Cfr. BARREDA FONTES, J. M.: Caciques y electores. Ciudad Real durante la Restauración, 1876-1923. Ciudad Real, 1986, p. 56. 
de los Gómez de Aramburu por el singular predominio de los Carranza en los dos primeros tercios de nuestro siglo ${ }^{11}$.

No es nuestra intención, sin embargo, penetrar aquí en el análisis del sistema caciquil gaditano, tema que está siendo ya objeto de investigaciones específicas ${ }^{12}$. Nos interesa ahora sólo señalar que, como afirma Espadas Burgos refiriéndose al conjunto del país, el régimen político instaurado en Cádiz a partir de 1875 es la obra de un reducido número de personas respaldadas por los restos de unos partidos políticos, por unos determinados sectores de la Iglesia y el Ejército y por unos grupos financieros, cuyos objetivos y cuyos programas no podían precisamente ufanarse de tener detrás ni siquiera de contar con el apoyo o con la opinión del pueblo* ${ }^{13}$. El nuevo régimen contará pues, desde un principio, con un alto grado de indiferencia, cuando no de abierto rechazo, en el pueblo gaditano, tan estrechamente vinculado a los experimentos revolucionarios del Sexenio.

La apatía de los gaditanos ante el sistema político de la Restauración se vio correspondida -y, a su vez, estimulada- por la actitud de absoluta indolencia ante los graves problemas de la ciudad que pusieron de manifesto los partidos oficiales ${ }^{14}$. En plena crisis comercial y portuaria, frustrados los intentos de sacar adelante una incipiente industria apoyada en los sectores textil y naval ${ }^{15}$, estancada social, demográfica y urbanísticamente ${ }^{16}$, Cádiz debió hacer frente no sólo al olvido, sino también a un claro obstruccionismo por parte de las autoridades, que pusieron trabas a todo intento de remontar la situación.

Si en otras zonas es posible percibir una cierta función benéfica. del sistema caciquil, en cuanto que éste fue capaz de responder a la demanda de intermediación entre una sociedad desarticulada, mayoritariamente rural, y las instancias administrativas, posibilitando a la postre la moderniza-

(11) Ramón de Carranza, casado con Josefa Gómez de Aramburu, fue diputado y senador maurista entre 1903 y 1918, y alcalde de Cádiz de 1927 a abril de 1931; con el golpe militar recuperó la alcaldia en 1936, muriendo poco después. Su hijo José León mantendría el control de la familia sobre la política local desde 1940 hasta su muerte en 1969.

(12) Por ejemplo, sobre Ramón de Carranza está trabajando J. Piñeico Blanca, cuya tesis doctoral La oligarquía gaditana en la crisis de la Restauración: la figura de Ramón de Carranza arrojará sin lugar a dudas nuevas luces acerca del sistema que posibilitó tal protagonismo político, social y económico.

(13) ESPADAS BURGOS, M.: Alfonso XII y los origenes de la Restauración. Madrid, 1975, p. 3.

(14) Vid. MILLAN CHIVITE, J. L.: -El controvertido Cádiz de la Restauración-. En: VARIOS: Provincia de Cädiz, III. Sevilla, 1984.

(15) Cfr. RAMOS SANTANA, A.: Panorama de la industrialización gaditana en la segunda mitad del siglo XIX. El sector textil y el sector naval. En: Actas de los III Coloquios de Historia de Andalucía. Historia Contemporánea, III. Córdoba, 1985, pp. 13-20.

(16) Cfr. PEREZ SERRANO, J.: -Demografía y urbanización: dos siglos de relaciones (17801980). En: Preactas del II Congreso de la Asociación de Demografía Histórica. Alicante, 1990 , pp. $654-670$. 
ción de las estructuras políticas, sociales y económicas ${ }^{17}$, en Cádiz el caciquismo constituyó simple y llanamente un sistema de dominación. Las prácticas caciquiles no tuvieron por efecto, como en otros lugares, el tránsito de una economía de base agraria a otra de tipo capitalista desarrollada. De hecho, sucedió lo contrario: Cádiz, que había vivido siempre de espaldas a las comarcas rurales de su entorno y que incluso había alentado una temprana industrialización ${ }^{18}$, se verá ahora forzada, por causa de la indiferencia y las trabas gubernativas, a depender del campo, y en concreto de las exportaciones de productos agropecuarios -principalmente vinodel marco de Jerez ${ }^{19}$, fracasados ya los intentos industrializadores.

En efecto, el caciquismo gaditano respondió casi exclusivamente al interés de los grupos oligárquicos locales, principales artífices y beneficiarios de la Restauración, empeñados en mantener su control sobre la economía, estableciendo para ello una estructura jurídico-política profundamente antidemocrática. De ahí que la dictadura de Primo de Rivera no sólo no ponga fin en Cádiz a las prácticas caciquiles, sino que las refuerce, pues el sistema continúa siendo necesario para contener la creciente demanda de reformas sociales. La acción de figuras que enlazan con el tronco de las grandes familias del XIX, como el propio Ramón de Carranza, revela con nitidez la pervivencia del modelo político en la nueva época.

Por lo dicho se explica el carácter especialmente represivo, casi policiaco, que poseyó el caciquismo gaditano ${ }^{20}$. La "pacificación. llevada a cabo por Manuel Pavía en los años de mayor efervescencia revolucionaria daría paso luego, restaurada la Corona, a un sistema de control social basado en el empleo sistemático de las detenciones preventivas ${ }^{21}$, el frecuente encarcelamiento de los líderes opositores ${ }^{22}$, la férrea censura de prensa ${ }^{23}$ y la restricción de las fiestas populares ${ }^{24}$.

(17) Vid. el desarrollo de esta tesis en VARELA ORTEGA, J.: Los amigos politicos, amigos, elecciones y caciquismo en la Restauración (1875-1900). Madrid, 1977. También TUSELL. GOMEZ, J.: -Modernización política en la España del primer tercio del siglo XX. Revista de la Universidad de Madrid, 81 (1973), pp. 183-201.

(18) Cfr. PEREZ SERRANO, J.: -Reconversión económica e incorporación de la mujer al trabajo en Cádiz durante el primer tercio del siglo XIX. En: Actas de los II Coloquios de Historias Locales de Cadiz, Cádiz, en prensa.

(19) De ahí el fuerte impacto que las crisis agrarias del periodo 1882-1903 tuvieron sobre la economía de la ciudad, Cfr. TEDDE DE LORCA, P.: .Un capitalismo precario.. En: DOMINGUEZ ORTIZ, A. (ed.): Historia de Andalucía, VIII. Barcelona, 1981, pp. 161 ss.

(20) Cfr. MILIAN CHIVITE, J. L.: •El Cádiz polémico...• op. cit., pp. 65-67.

(21) Buena prueba de ello fueron las extremadas medidas de seguridad adoptadas de cara a la movilización del 1 de Mayo de 1890, con detenciones masivas de líderes opositores, de las que se hicieron eco todos los periódicos locales.

(22). Es el caso, por ejemplo, de Fermín Salvochea, detenido primero con carácter preventivo y luego condenado a cadena perpetua como agitador revolucionario.

(23) Véase la airada protesta contenida en el temprano editorial de La Verdad, el 24 de febrero de 1875, motivada por la implantación de la censura de prensa por parte de los nuevos gobernantes.

(24) El Carnaval sufrió especialmente estas restricciones. Por ejemplo, Vid. .El Carnaval. El Noticiero Gaditano, 25 de enero de 1921, p. 3. 
En la justificación de estas medidas los defensores del turnismo nos trazarán un cuadro altamente expresivo de cuál era a sus ojos la situación política local: ‘Una red criminal envuelve a España, el sindicalismo se ampara en el terrorismo [...] No son tiempos de caretas ni aglomeraciones anónimas éstos en que en Cádiz se curan heridos, el gobernador no duerme y la policía inquiere la vigilancia ${ }^{25}$. Las referencias en el mismo sentido podrían acumularse si atendemos a lo expresado por los medios afines al sistema; en síntesis todos vienen a concluir que el modelo es necesario y, por ende, que sus formas están justificadas por la inestabilidad social y política existente en la ciudad. Es éste un discurso que estará presente en los ámbitos cercanos a la élite caciquil gaditana desde 1875 hasta el final de la dictadura de Primo. Y aún después, pues será usado como caballo de batalla de la propaganda monárquica durante la II República.

\section{LA RESPUESTA CRITICA AI. SISTEMA CACIQUIL: DESCENTRAIIZACION POLITICA, REFORMAS SOCIOECONOMICAS Y AUTONOMIA MUNICIPAL}

Reseñadas las carencias del caciquismo gaditano en lo que se refiere a hacer frente a los problemas reales de la ciudad, resultará comprensible que desde muy pronto comiencen a oirse voces discrepantes. Ya hemos adelantado que los contenidos básicos de la crítica al sistema caciquil en Cádiz manifiestan una sorprendente afinidad con las principales formulaciones del regionalismo andaluz, $\tan$ limitado sin embargo en el terreno organizativo ${ }^{26}$.

Tres serán las más propuestas más repetidas: la reforma del modelo de Estado y del sistema electoral, en el camino de la descentralización y la democratización; la ampliación de las libertades públicas, asociada a una profunda reforma en el régimen de la propiedad cuando se trata de medios obreros o republicanos; y la participación ciudadana en la gestión del municipio, dotando a éste de plena autonomía para el desarrollo de sus funciones básicas. Si echamos un vistazo a los temas más tratados por Blas Infante en los mismos años comprobaremos hasta qué punto

(25) .Las restricciones al Carnaval. El Noticiero Gaditano, 22 de enero de 1921, p. 4.

(26) Para llevar a cabo este análisis se han consultado las series completas de cuatro periódicos de distintas tendencias: el Diario Liberal (turnista), El Progreso (democrático), El Correo de Cádiz (católico) y El Reformista (republicano). Junto a ellos, para el último cuarto del XIX: El Clamor de Cädiz, El Correo Gaditano, La Dinastía, La Nueva Era, El Liberal Reformista, el Boletín Gaditano, el Noticiero Gaditano, La Verdad y el Diario de Cádiz. Para el primer tercio del XX, además de los citados: $E l$ Observador, $E l$ Porvenir de Cádiz, el Diario Conservador, La Opinión, y El Popular. 
existe sintonía entre sus propuestas y las demandas reformadoras de los críticos gaditanos ${ }^{27}$.

¿Cómo podría interpretarse esta afinidad? Desde luego no como resultado de una influencia del andalucismo en la opinión pública gaditana. Más oportuno sería, en todo caso, hablar de una confluencia de ambas posiciones, sobre la base de que en Cádiz la respuesta regionalista contó ya desde muy pronto con un singular y arraigado precedente: el gaditanismo, regionalismo. atípico circunscrito al área gaditana, que dominó la opinión pública local hasta la segunda década de nuestro $\operatorname{siglo}^{28}$. De hecho, el gaditanismo fue la vía, ciertamente peculiar, por la que el regeneracionismo costista logró penetrar y echar raíces en el Cádiz de la Restauración.

No es de extrañar; por tanto, que en su discurso crítico los gaditanos manifiesten numerosas concomitancias con los puntos de vista de los regionalistas andaluces, lo que, a primera vista, sin tener en cuenta esto, pudiera parecer poco justificable, dada la escasa implantación orgánica e influencia electoral de los andalucistas. Será en un segundo momento, atravesado ya por la crisis el sistema de la Restauración, cuando los postulados específicos del andalucismo comiencen a encontrar cierto eco en la opinión de los gaditanos, sustituyendo sus propuestas a las de un gaditanismo ya manifiestamente inviable.

La fecha de 1898 y, más claramente, la crisis política de la segunda década del nuevo siglo, marcarán este tránsito. No existirá, sin embargo, ruptura en lo que se refiere a los argumentos centrales del discurso crítico, en la actitud de los gaditanos con respecto al caciquismo y en su intransigente defensa de las mayores cotas de autonomía municipal. De hecho, hasta 1936 ambas tendencias coexisten y se entrelazan en la opinión pública gaditana.

\subsection{El caciquismo visto por el gaditanismo: una denuncia empirica y una respuesta insolidaria.}

Ya hemos señalado que el caciquismo, vverdadera constitución real del país. ${ }^{29}$ durante la época de la Restauración, fue objeto primeramente de la crítica gaditanista. El sombrío panorama de la ciudad en estos años

(27) En particular los artículos publicados por Infante entre junio de 1916 y septiembre de 1917 en la revista Andalucia, órgano del regionalismo sevillano. Vid. SORIANO DIAZ, L.: -Aspectos de la filosofía política de Blas Infante. En: Actas del I Congreso... op. cit., II, pp. 483-495.

(28) Vid. PEREZ SERRANO, J.: Gaditanismo y andalucismo.... op. cit., pp. 409-427.

(29) FERRANDO BADIA, J.: .Prólogo.. En: SANCHEZ FERRIZ, R.: La Restauración y su Constitución Política. Valencia, 1984, p. 9. 
propició, en efecto, que pronto se desvaneciese toda esperanza de una regeneración que llegara de la mano de los partidos del turno. La rebeldía de los gaditanos desembocará así en la denuncia de la ‘marginación. y el "olvido* con que los caciques locales y los nuevos gobernantes de Madrid enfocan los acuciantes problemas de la ciudad.

Sin embargo, paralelamente, es posible encontrar una profunda autocrítica que atribuye a la indiferencia y a la falta de capacidad de reacción de los propios gaditanos la consolidación y el mantenimiento del sistema caciquil ${ }^{30}$. Aunque esta última posición predomina en medios que no son abiertamente beligerantes con el caciquismo, a nuestro juicio, no debe ser interpretada como un argumento exculpativo para con él, sino más bien como reflejo de una estrategia más modesta, que ve en el cambio de actitud de los ciudadanos la única vía para llevar a cabo la regeneración. *Cádiz tiene que olvidar su abandono abúlico de siempre, su facilidad para dejarse dominar por un indiferentismo sui generi que ha logrado petrificar las iniciativas de todas las clases ${ }^{31}$, se dirá en un paradigmático llamamiento aparecido en la portada del Diario de Cádiz. ¿No son acaso éstas que se denuncian condiciones básicas para la subsistencia del sistema caciquil?

Junto a esta crítica velada, indirecta, encontramos un discurso de corte más agresivo en otros medios que se hacen eco también de las propuestas gaditanistas. Es posible afirmar que la valoración mayoritaria es negativa en lo que se refiere a la actividad de los políticos del turno, excepción hecha de los tres grandes caciques señalados, a los que la opinión pública trata a veces como auténticos benefactores ${ }^{32}$. Lo más frecuente, sin embargo, será encontrar alusiones a un ‘Cádiz prisionero y esclavo", rendido ante unos políticos y ante un gobierno que «derrocha en cosas innecesarias, mientras que otros problemas más graves no se solventan, ${ }^{33}$. El gaditano de la época tiene la sensación de que los poderes públicos instalados en 1875 son en última instancia responsables, por su abandono, de que los beneficios del pasado esplendor de la ciudad sean *ofrendados a explotadores", y de que se cierre el camino de la política a los "hombres virtuosos", lo que constituye una clara alusión a la manipulación de los mecanismos electorales ${ }^{34}$. En efecto, para muchos

(30) A. Virtubey se quejará, por ejemplo, de que el gaditanismo consiste en ocultar las llagas, en lugar de descubrirlas para que se curen., Cfr. Diario de Cádiz, 12 de septiembre de 1913, p. 2.

(31) Diario de Cádiz, 20 de febrero de 1920, p. 1.

(32) Es el caso de Cayetano del Toro, cuya memoria perduró largamente entre los gaditanos, que acordaron conmemorar la fecha de su muerte, el 7 de agosto, Diario de Cádiz, 7 de agosto de 1917.

(33) El Progreso, 16 de marzo de 1912, p. 2.

(34) El Reformista, 31 de enero de 1923, p. 1. 
-Cádiz padece la enfermedad general de dejar impasible que las mayorías liberales, ineptas, fruto del caciquismo, la sigan administrando. ${ }^{35}$.

Es cierto que no se trata tanto de una crítica al sistema político como tal, cuanto de una denuncia amarga de sus sonsecuencias de toda índole para la ciudadanía. Lo que indigna a los gaditanos no es, digámoslo así, la esencia antidemocrática o fraudulenta del caciquismo, sino las circunstancias concretas que se derivan de su aplicación ${ }^{36}$. Son, por tanto, sus efectos -y casi nunca su naturaleza- los que provocan el rechazo social al sistema. De hecho, aun conscientes de las limitaciones del modelo político, no faltarán en estos años los llamamientos a los diputados gaditanos para que trabajen unidos en pro de la ciudad ${ }^{37}$. Será la práctica la que vaya poniendo de manifiesto, en palabras del radical Sánchez Robledo, «la imposibilidad en que se encuentran las actuales Cortes para conceder beneficios a Cádiz, ${ }^{38}$.

Paralelamente, los partidos opisitores, desde los católicos hasta los republicanos, demandarán de la ciudadanía testimonio de gaditanismo en las elecciones", identificando abiertamente la defensa de la "región gaditana* con la censura a los partidos del turno y, por ende, al sistema caciquil ${ }^{39}$. Tan arraigada estará esta valoración negativa de lo que significa el caciquismo en la opinión pública local que los propios conservadores gaditanos, al rechazar las propuestas del regionalismo andaluz, argumentarán, antes que otras cosas, que éstas suponen jextender la tela de araña del caciquismo sevillano por toda o por casi toda Andalucía $!^{40}$ Es obvio que buscan ante todo preservar su ffeudo", pero no es difícil entrever que la alusión explícita al caciquismo se considera potencialmente :útil. para provocar el rechazo hacia la propuesta que lo lleva asociado.

\subsection{El caciquismo visto por el andalucismo: una crítica teórica y una propuesta solidaria.}

Aunque hace su aparición más tardiamente en la opinión pública gaditana, el andalucismo dará una mayor coherencia y profundidad a la crítica anticaciquil. Su visión, más de conjunto, explicativa y teórica, supondrá un avance en la comprensión del auténtico significado del caciquismo

(35) El Correo de Cádiz, 6 de noviembre de 1913, p. 1.

(36) Veamos una sombría descripción de la ciudad poco antes del golpe de Primo: ael pueblo de Cádiz [...] llora de hambre, de inanición, en todos los oficios falta trabajo, la miseria se multiplica, la tuberculosis hace estragos [...], La Opinión, 16 de diciembre de 1921, p. 50.

(37) -Antes de políticos, somos gaditanos, y posponemos la política a todo aquello que represente un beneficio para esta ciudad que tanto amamos [...]., El Porvenir de Cádiz, 5 de marzo de 1916. p. 2.

(38) Diario de Cádiz, 1 de junio de 1916, p. 1.

(39) El Correo de Cádiz, 6 de noviembre de 1913, p. 1.

(40) Diario Conservador, 4 de septiembre de 1915, p. 1. 
para la ciudad y, por ello, constituirá una eficaz ayuda a la hora de definir los grandes parámetros del proyecto regeneracionista gaditano en el primer tercio del XX. El gaditanismo decimonónico se había quedado en la machacona denuncia de la perniciosa influencia del sistema político sobre las condiciones materiales de vida de la ciudad. En cambio, la penetración del andalucismo llevará a ampliar la perspectiva. El problema del caciquismo comenzará a verse desde un prisma fundamentalmente ideológico, como una negación de los principios de libertad, democracia y autonomía en que el regionalismo se asienta. Como resultado de esta influencia, la prensa local acabará convirtiéndose en tribuna para llevar a cabo una despiadada crítica de los orígenes, las raíces y la naturaleza del caciquismo, considerado ahora como un sistema integral, nocivo no sólo para Cádiz sino para el conjunto de Andalucía.

El estancamiento político, social y económico de Cádiz se irá vinculando lentamente a la situación general de marginación que sufre Andalucía en el marco del Estado centralizado, lento y burocrático que impuso la Constitución de $1876^{41}$. De ahí que arrecien las críticas al caciquismo, asociado ahora abiertamente al "odioso sistema centralizador", al que se considera responsable último de todos los males que aquejan a Andalucía. Cuestiones como la creciente emigración de trabajadores andaluces a Gibraltar ante la falta de expectativas económicas en la región ${ }^{42}$, la represión sistemática del movimiento obrero y campesino ${ }^{43}$ y el trato preferente otorgado por el gobierno central a otras regiones y países ${ }^{44}$, fueron despertando en Cádiz en estos años una incipiente solidaridad con el resto de Andalucía.

Aunque nunca floreció en Cádiz una prensa específicamente andalucista ${ }^{45}$, ya en la segunda década del XX domina en las capas burguesas y los sectores intermedios de la sociedad gaditana la idea de que no es posible la tan ansiada regeneración sin el relanzamiento paralelo del entorno andaluz. La misma convicción reflejan, desde otro punto de vista, las cada vez más freuentes manifestaciones de solidaridad de los obreros gaditanos con los de otras provincias andaluzas, justificadas, se dirá, por la defensa de intereses comunes.

(41) Cfr. ARTOLA, M.: Partidos y programas políticos, 1808-1936. Madrid, 1977, pp. 323-324.

(42) Cfr. El Correo de Cádiz, 1 de abril de 1918, p. 2.

(43) Cfr. Juácaro, 26 de julio de 1919, entrevista con Sebastián Oliva, líder campesino encarcelado en Cádiz.

(44) Cfr. Diario de Câdiz, 22 de agosto de 1913, p. 2.

(45) Habría quizás que exceptuar el semanario Alma Andaluza, aparecido en 1919. En la provincia sí tuvieron cierta difusión periódicos andalucistas como El Justiciero, de El Puerto de Santa María, o El Labrador, de Algeciras, coetáneos del semanario gaditano, Cfr. LACOMBA, J. A.: El andalucismo, Blas Infante y Cádiz. En: Cádiz en su bistoria. IV Jornadas de Historia de Cádiz. Cádiz, 1985, 134 ss. 
En este contexto se explica la tendencia a constituir secciones autónomas en los principales partidos de la oposición al turnismo y, fuera ya de este marco, la expansión de un movimiento tan radicalmente crítico con el sistema caciquil como fue el anarquismo agrario andaluz. Es sintomático de lo que venimos diciendo el hecho de que la opinión pública gaditana nunca condenó tajantemente la actividad de los anarquistas, ni mostró excesiva combatividad ante otra respuesta, menos organizada y consciente, pero igualmente crítica respecto al sistema: el bandolerismo, reconocido como un fenómeno propio. vinculado a las precarias condiciones de vida del campesinado y a la asfixiante presión del caciquismo rural ${ }^{46}$. Difícilmente estaban legitimados para hacer respetar la ley unos políticos que habían hecho del ssufragio universal [...] la trampa electoral como sistema.47.

$\mathrm{El}$ avance en la consideración del origen fundamentalmente político de estos fenómenos llevará a plantear cada vez con mayor insistencia la necesidad de cambiar el sistema. En Cádiz, peculiar sociológica e históricamente respecto al resto de Andalucía, quedarán en segundo plano hasta bien entrado nuestro siglo elementos como la afirmación de una cultura común o el reconocimiento de una poco asumida identidad como pueblo: la crítica regionalista tendrá como eje el rechazo al centralismo. Y ello porque la descentralización política estará íntimamente unida en la mente de los gaditanos a la reforma de las estructuras socioeconómicas y, por ende, a la salida de la prolongada crisis que había dominado la ciudad en la segunda mitad del XIX ${ }^{48}$. El caciquismo, por su parte, fue siempre considerado un obstáculo para ambas pretensiones, lo que en sí explica la falta absoluta de respaldo que encontró en la opinión pública gaditana ${ }^{49}$.

Las diversas vertientes de la crítica anticaciquil quedan recogidas en una tercera reivindicación regionalista que en Cádiz logró sintetizar las dos grandes aspiraciones citadas: la autonomía municipal. Esta propuesta contaba con un sólido respaldo en la ciudadanía, forjado en la experiencia federalcantonalista, pero se había mantenido fuera del debate político

(46) Vịd. El Clamor de Cádiz, 10 de septiembre de 1886, p. 1. La misma actitud poco beligerante mostrará la prensa gaditana en lo que se refiere a los sucesos de La Mano Negra (1883) o ante El Asalto a Jerez (1892).

(47) MiLlaN CHIVITE, J. L.: •El Cádiz polémico de la Restauración... - op. cit., p. 67.

(48) Ya vimos que el gaditanismo había responsabilizado al Estado centralista de la falta de inversión y, por tanto, de la desindustrialización de la ciudad, Vid. El Liberal Reformista, 10 de marzo de 1888 , p. 1.

(49) En modo alguno cabría hablar aquí de lo que algunos autores denominan -caciquismo deferencial., propio de sistemas descentralizados (la Inglaterra de Jorge III, por ejemplo). Mayor similitud existe con el sistema político instaurado en Francia por Napoleón III, en el que los elementos coactivos de origen externo jugaron un importante papel. Vid, THOMPSON, E. P.: La formación histórica de la clase obrera. Barcelona, 1977. 
por razones obvias en la plenitud de la Restauración. La crisis del sistema durante la segunda década del nuevo siglo posibilitará la expresión pública de las nunca desterradas aspiraciones de los gaditanos a la autonomía del municipio, ahora al calor de la incipiente agitación regionalista, que había hecho suya esta reivindicación ${ }^{50}$. Tal era la potencialidad que en este sentido se le atribuía al regionalismo, que incluso los propios partidos del turno llegaron a lamentarse en alguna ocasión por la debilidad de unas ideas que, a su juicio, podían servir a Cádiz para presionar a Madrid en la defensa de los intereses locales ${ }^{51}$.

El apoyo de la opinión pública a la autonomía municipal era unánime. Ante el pueblo se presentaba como la fórmula más eficaz de eliminar la influencia de las redes caciquiles, pues se asociaba al incremento de la participación ciudadana en el gobierno del municipio y en el control de la gestión ${ }^{52}$. Para los sectores burgueses era también una propuesta deseable, pues suponía la posibilidad de recuperar la iniciativa en la vida pública, lo que les permitiría, pensaban, disponer de medios para fomentar la reactivación de la economía local. Obviamente no se trataba ya de una autonomía tendente al cantonalismo ${ }^{53}$, sino de conquistar un grado de libertad consistente en esencia en la quiebra de los vínculos que, a traves del tejido caciquil, subordinaban las aspiraciones de la ciudadanía a los intereses de los círculos oligárquicos que controlaban el gobierno central.

En este contexto, los andalucistas ofertaban una forma de organización "contrapuesta a la [...] de los partidos caciquiles" ${ }^{54}$, los Centros Andaluces, que comenzaron a extenderse a partir de 1916. Aunque los gaditanos no acogieron con entusiasmo la idea de encuadrarse en este movimiento, la opinión pública local refleja, no obstante, una creciente demanda de leyes especiales y medidas urgentes para revitalizar slas

(50) Uno de los periódicos más comprometidos con la autonomía municipal, El Reformista, era a la vez el principal difusor del regionalismo programático entre los gaditanos, para lo cual contaba con una sección fija titulada explícitamente .En defensa de la región.

(51) Por ejemplo, en la polémica suscitada por la falta de respuesta del gobierno a las demandas urgentes del puerto gaditano, Cfr. Diario Liberal, 16 de octubre de 1914, p. 1. Estos posicionamientos deberían interpretarse a la luz del giro anticentralista que comienzan a manifestar los partidos del turno en el conjunto del país. Recuérdese la activa campaña promovida en este sentido por El Liberal, de Sevilla, en el mismo año 1914.

(52) Algunos iban más allá, proponiendo establecer una mancomụnidad autónoma que abarcase al conjunto de municipios de la Bahía, Cfr. El Reformista, 15 de septiembre de 1912, p. 1.

(53) La crítica regionalista en Cádiz durante estos años se orienta por igual al -centralismo madrileño. y al separatismo vasco y catalán. Entre otros testimonios, Vid. El Correo de Cádiz, 8 de junio de 1916, p. 2; El Progreso, 30 de noviembre de 1918, p. 1.

(54) INFANTE, B.: La verdad sobre el complot de Tablada y el Estado Libre de Andalucía. Granada, 1979, p. 107. 
anquilosadas estructuras de la región. 55 , asumiendo el principio regionalista de que el total desmantelamiento del sistema caciquil debe ser considerado condición indispensable para el avance de cualquier reforma, por modestos que sean sus objetivos ${ }^{56}$.

En suma, podemos concluir que en Cádiz la crítica al sistema caciquil se centra precisamente en los tres aspectos que podríamos considerar esenciales de su práctica política: el control absoluto de las instituciones representativas, la represión sistemática de los descontentos y el desinterés de las autoridades centrales respecto a los problemas de la ciudad. Este monopolio del poder político al servicio de los intereses del bloque oligárquico artífice de la Restauración fue denunciado desde muy pronto por la opinión pública gaditana, en un discurso crítico de corte regeneracionista basado esencialmente en las propuestas descritas: descentralización del poder político, reforma de las estructuras que sustentan las desigualdades sociales y reconocimiento de la plena autonomía del municipio.

Es posible distinguir, a partir de los elementos contenidos en la crítica al sistema político, dos etapas que manifiestan el progreso de la ciudadanía en la comprensión de la auténtica naturaleza del problema. En una primera fase, que abarcaría el último cuarto del XIX, la crítica está dominada por los argumentos del gaditanismo, es decir: denuncia de las consecuencias concretas que para la ciudad tiene el sistema instalado en 1875 y defensa de una regeneración local a partir de las propias energías latentes, estimulada por una profunda autocrítica que permita al pueblo recuperar la iniciativa. Tras unos años de transición en que conviven ambas conceptualizaciones, en la segunda década del XX el discurso crítico estará dominado ya por los argumentos centrales del andalucismo: rechazo frontal del sistema político, social y económico que impide resolver los graves problemas de la ciudad y propuesta de una regeneración surgida del esfuerzo mancomunado de todos los andaluces, fruto del arraigo de valores como la solidaridad regional.

(55) El Progreso, 1 de julio de 1916, p. 1.

(56) Cfr. El Correo de Cádiz, 6 de marzo de 1917, p. 1. 